\title{
Analysis of Development Factors of Central Plains Aviation Logistics Based on ISM
}

\author{
Xiong Ying \\ Institute of logistics,Henan Communication Vocational Technology College, Zhengzhou 450052 , \\ China \\ xiongying67@126.com
}

Keywords: air logistics of central plains; influencing factors; interpretive structural modeling method

\begin{abstract}
Aviation logistics is emerging economies form and rapidly develops with the construction of air port. At present, the central plains of aviation logistics industry is rapidly developing, which can not only promote the economic development, offer opportunities of jobs and career, and become a driving force of economic development in the new urban growth pole, but also affect the adjustment of industrial structure, enhance the Zhengzhou international economy status. However, in the process of the development, it may meet a lot of influence factors, this paper does some analysis and research on some problems of the aviation logistics in the process of construction in Zhengzhou. According to system analysis of interpretive structural modeling method, some constructive suggestions of the development of the central plains aviation logistics are given.
\end{abstract}

\section{Introduction}

Aviation Logistics, an important branch of modern logistics industry, is fast growing along with economic of China rapid development, and its main mode is air transport, which prompts effective transfer of goods from the origin (supply) to the destination (demand) by using modern information technology. Its main feature is efficient and fast[1-3]. From the end of the last century, the demand for air transport is rapid growing with globalization economic deepening. In the fierce competition with the maritime and air transport, air cargo has reached at $40 \%$ of world trade in the value. According to the International civil Aviation Association predicting, the world air cargo business will almost increase triple in next 20 years. Therefore, the air logistics industry is becoming more and more important[4-5].

With the developing of economic globalization and regional integration and central economic region, and facilitating the strategy of central China, the Central Plains area economy has been greatly improving, whose developing has been also leading to the development of industries, including aviation logistics, however, there are some problems during the developing of aviation logistics in Zhongyuan district.

The 'Central Plains Economic Zone' and 'Development Plan of Zhengzhou Airport Economic Comprehensive Experimental Zone' are approved by State Council of China in November 2012 and March 2013, respectively. This is the first national strategy pioneering district of airport economic development, which plays a role of the core growth of Central Plains Economic Zone and the strategic task of 'big hub, big industry and metropolis'. For a landlocked Central Plains Economic Zone, the development of airport economic can innovate to a new path, generating new agglomeration and diffusion effects, breaking through bottlenecks of location and resources, complying with the developments of intelligent, digital, green, light and new industrialization. It is rapidly integrating into global value chains division system, compensating the shortage of fund, technology, talents and markets opportunity compared with the coastal areas, achieving regional economic rapid development. These two documents approved by State Council of China, supply a significant developing opportunity for Zhengzhou air cargo industry, and the construction of comprehensive experimental zone will inevitably promote the development of aviation logistics, which will also promote the development of other industries[6]. 
The reasons of air logistics of central plains rapidly developing come from the development of international financial markets make the domestic economy constantly improve and the policy of 'promoting the rise of central region planning' from Chinese government. All of these will effectively promote the economic structure upgrade of Henan province, stimulate consumption, optimize industrial structure and enlarge the needs of air transport. There will encounter many problems in the process of rapidly developing. Based on the economic characters of central plains, this paper analyses the main factors influencing the developing of the air logistic, builds up interpretive structural modeling and supplies some constructive suggestions.

\section{Interpretative Structural Modeling Method}

Interpretative structural modeling method (referred ISM) technology was founded by professor Warfield in 1973, mainly using for the analysis of complex structural problems of socio-economic system, on the other hand, it decomposes complicated system into many subsystems. Using this method, a multi-level hierarchical structure model is built up with practical experience, knowledge and the help provided by computer.

According on logical operations of adjacent matrix with ISM, a reachability matrix is founded first, and which is decomposed, then a complex system turns into a clear multi-level hierarchical form. Its main steps are listed as: step one is organizing the ISM group, step two is setting the key problems, step three is selecting the key factors of system, step four is listing the relations of these factors, step five is establishing adjacency and reachablility matrixes according these relationship, step six is building the structural model based on the decomposition of the matrix, step seven is establishing interpretive structural modeling according to the structural model.

\section{Affecting factors analysis of the development of aviation logistics industry in central plains}

The development of aviation logistics in central plains district is at the initial stage, and it will inevitably meet some problems in its exploration process. In this paper, according to collecting literature, surveying, statistic analysis and actual situation, some main influence factors are found out and shown in Table 1.

Table1 The influence factors of aviation logistics in central plains

\begin{tabular}{cc}
\hline number & Factors Name \\
\hline S1 & Knowledge of aviation logistics \\
S2 & Lack of professionals \\
S3 & The structure of freight market \\
S4 & Aviation Logistics information \\
S5 & Infrastructure \\
S6 & The level of modern logistics \\
S7 & Air logistics service platform \\
S8 & The level of management \\
S9 & Consciousness of consumer \\
S10 & Policies and regulations \\
S11 & The development level of aviation logistics \\
\hline
\end{tabular}

Combined with the actual development of the central plains district, some research on those factors listed in Table 1 is carried out. The relationships between these factors are shown in Figure 1. 


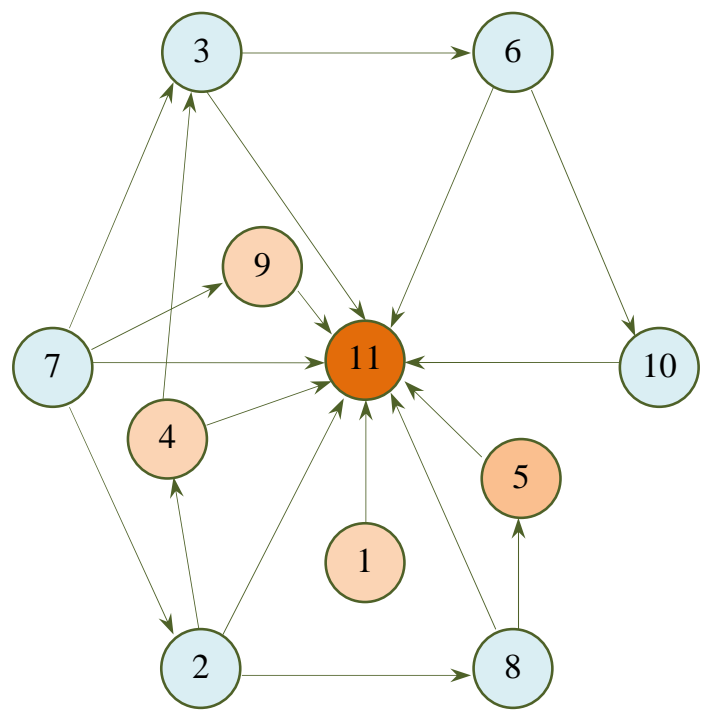

Fig. 1 The digraph of the aviation logistics factors of central plains

\section{Adjacency matrix introduction}

Adjacency matrix is used to describe the direct relationship between the elements of system, using a $m \times m$ phalanx to express, $m$ represents the number of elements of system, if $A=\left(a_{i j}\right)_{m \times m}$, then we can receive:

$$
a_{i j}= \begin{cases}1, & \text { if there is relation between } s_{i} \text { and } s_{\mathrm{j}} \\ 0, & \text { if there is no relation between } s_{i} \text { and } s_{\mathrm{j}}\end{cases}
$$

According to analysis, the relationship between these elements is received, and the adjacent matrix founded follows:

$$
\begin{aligned}
& \begin{array}{lllllllllll}
S_{1} & S_{2} & S_{3} & S_{4} & S_{5} & S_{6} & S_{7} & S_{8} & S_{9} & S_{10} & S_{11}
\end{array} \\
& s_{1} s_{2}\left[\begin{array}{lllllllllll}
0 & 0 & 0 & 0 & 0 & 0 & 0 & 0 & 0 & 0 & 1 \\
0 & 0 & 0 & 1 & 0 & 0 & 1 & 0 & 0 & 0 & 1
\end{array}\right] \\
& \begin{array}{l|lllllllllll}
s_{3} & 0 & 0 & 0 & 0 & 0 & 0 & 0 & 0 & 0 & 1 & 1
\end{array} \\
& \begin{array}{l|lllllllllll}
s_{4} & 0 & 0 & 1 & 0 & 0 & 0 & 1 & 0 & 0 & 0 & 1
\end{array} \\
& \begin{array}{l|lllllllllll}
s_{5} & 0 & 0 & 0 & 0 & 0 & 0 & 0 & 0 & 0 & 0 & 1
\end{array} \\
& A=s_{6} \quad \begin{array}{llllllllllll}
0 & 0 & 0 & 0 & 0 & 0 & 0 & 0 & 1 & 0 & 1
\end{array}
\end{aligned}
$$

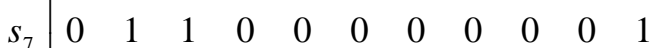

$$
\begin{aligned}
& \begin{array}{l|lllllllllll}
s_{8} & 0 & 0 & 0 & 0 & 1 & 0 & 0 & 0 & 0 & 0 & 1
\end{array} \\
& \begin{array}{l|lllllllllll}
s_{9} & 0 & 0 & 0 & 0 & 0 & 0 & 0 & 0 & 0 & 1 & 1
\end{array} \\
& s_{10}\left[\begin{array}{lllllllllll}
0 & 0 & 0 & 0 & 0 & 0 & 0 & 0 & 1 & 0 & 1
\end{array}\right. \\
& s_{11}\left[\begin{array}{lllllllllll}
0 & 0 & 0 & 0 & 0 & 0 & 0 & 0 & 0 & 0 & 0
\end{array}\right]
\end{aligned}
$$

\section{Reachability Matrix}

Use of adjacency matrix in unit matrix $I$, we now derive $A+I$. Using Boolean operation rules, we execute power calculation $(A+I)^{k}$, until all the product of which after a power law is equal, and the result is reachability matrix. It can be written as:

$$
(A+I)^{k-1} \neq(A+I)^{k}=(A+I)^{k+1}
$$

Where $M=(A+I)^{k}$ is reachability matrix.

Using matlab program, reachability matrix can be derived in the form: 


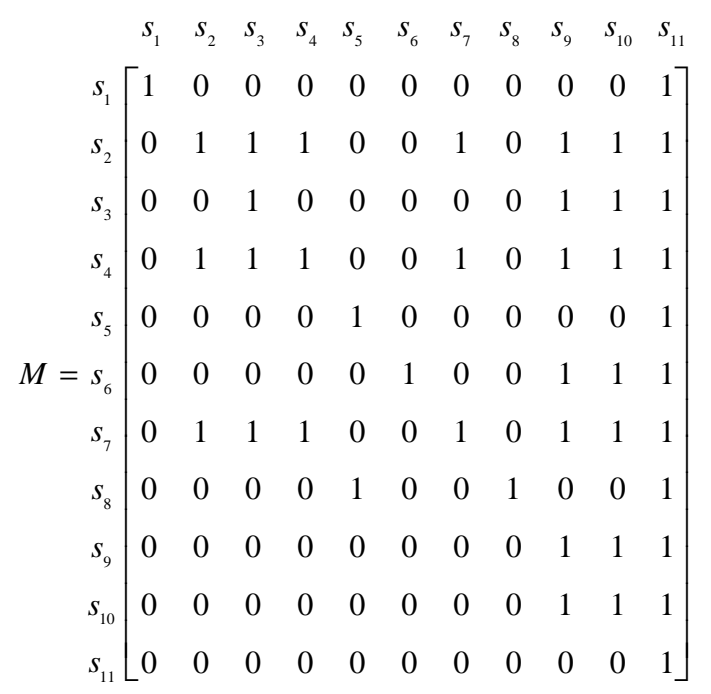

\section{Hierarchical decomposition of reachability matrix}

The aim of hierarchical decomposition of reachability matrix mainly makes the relationship between these elements clear, the top level of which represents the ultimate goal of system, and the following layer successively represents the layer of hierarchica. In the process of calculation, reachability set, first set and the highest elements set are needed. Reachability set $R\left(S_{i}\right)$ is the set of all column elements equal to 1 , which belongs to the row elements of $S_{i}$ in the reachability matrix. First set $Q\left(S_{i}\right)$ is the set of all row elements equal to 1, which belongs to the column elements of $S_{i}$ in the reachability matrix. the highest elements set is $R\left(S_{i}\right)=R\left(S_{i}\right) \cap Q\left(S_{i}\right)$.

Based on the above definition, after getting the highest elements of the first stage in reachability matrix $M$, the row and column of which stated are be deleted. Then in the same way, the next highest elements of the residue matrix are received, and step by step, all the elements are classified clearly. Specific levels divided as shown in Table 2 to Table 5.

Table2 First stage element

\begin{tabular}{cccc}
\hline$S_{i}$ & $R\left(S_{i}\right)$ & $Q\left(S_{i}\right)$ & $R\left(S_{i}\right) \cap Q\left(S_{i}\right)$ \\
\hline$S_{1}$ & 1,11 & 1 & 1 \\
$S_{2}$ & $2,3,4,7,9,11$ & $2,4,7$ & $2,4,7$ \\
$S_{3}$ & $3,9,10,11$ & $2,3,4,7$ & 3 \\
$S_{4}$ & $2,3,4,7,9,10,11$ & $2,4,7$ & 4,7 \\
$S_{5}$ & 5,11 & 5,8 & 5 \\
$S_{6}$ & $6,9,10,11$ & 6 & 6 \\
$S_{7}$ & $2,3,4,7,9,10,11$ & $2,4,7$ & $2,4,7$ \\
$S_{8}$ & $5,8,11$ & 8 & 8 \\
$S_{9}$ & $9,10,11$ & $2,3,4,6,7,9,10$ & 9,10 \\
$S_{10}$ & $9,10,11$ & $2,3,4,6,7,9,10$ & 9,10 \\
$S_{11}$ & 11 & $1,2,3, \cdots, 11$ & 11 \\
\hline
\end{tabular}

Table3 Second level elements

\begin{tabular}{cccc}
\hline$S_{i}$ & $R\left(S_{i}\right)$ & $Q\left(S_{i}\right)$ & $R\left(S_{i}\right) \cap Q\left(S_{i}\right)$ \\
\hline$S_{1}$ & 1 & 1 & 1 \\
$S_{2}$ & $2,3,4,7,9$ & $2,4,7$ & $2,4,7$ \\
$S_{3}$ & $3,9,10$ & $2,3,4,7$ & 3 \\
\hline
\end{tabular}




\begin{tabular}{cccc}
\hline$S_{4}$ & $2,3,4,7,9,10$ & $2,4,7$ & 4,7 \\
$S_{5}$ & 5 & 5,8 & 5 \\
$S_{6}$ & $6,9,10$ & 6 & 6 \\
$S_{7}$ & $2,3,4,7,9,10$ & $2,4,7$ & $2,4,7$ \\
$S_{8}$ & 5,8 & 8 & 8 \\
$S_{9}$ & 9,10 & $2,3,4,6,7,9,10$ & 9,10 \\
$S_{10}$ & 9,10 & $2,3,4,6,7,9,10$ & 9,10 \\
\hline
\end{tabular}

Table 4 Third level elements

\begin{tabular}{cccc}
\hline$S_{i}$ & $R\left(S_{i}\right)$ & $Q\left(S_{i}\right)$ & $R\left(S_{i}\right) \cap Q\left(S_{i}\right)$ \\
\hline$S_{2}$ & $2,3,4,7$ & $2,4,7$ & $2,4,7$ \\
$S_{3}$ & 3 & $2,3,4,7$ & 3 \\
$S_{4}$ & $2,3,4,7$ & $2,4,7$ & 4,7 \\
$S_{6}$ & 6 & 6 & 6 \\
$S_{7}$ & $2,3,4,7$ & $2,4,7$ & $2,4,7$ \\
$S_{8}$ & 8 & 8 & 8 \\
\hline
\end{tabular}

Table5 Fourth level elements

\begin{tabular}{cccc}
\hline$S_{i}$ & $R\left(S_{i}\right)$ & $Q\left(S_{i}\right)$ & $R\left(S_{i}\right) \cap Q\left(S_{i}\right)$ \\
\hline$S_{2}$ & $2,4,7$ & $2,4,7$ & $2,4,7$ \\
$S_{4}$ & $2,4,7$ & $2,4,7$ & $2,4,7$ \\
$S_{7}$ & $2,4,7$ & $2,4,7$ & $2,4,7$ \\
\hline
\end{tabular}

According to the above tables, all elements of reachability matrix are classified in four levels, in the form: $L_{1}=\left\{S_{11}\right\}, L_{2}=\left\{S_{1}, S_{5}, S_{9}, S_{10}\right\}, L_{3}=\left\{S_{3}, S_{6}, S_{8}\right\}, L_{4}=\left\{S_{2}, S_{4}, S_{7}\right\}$.

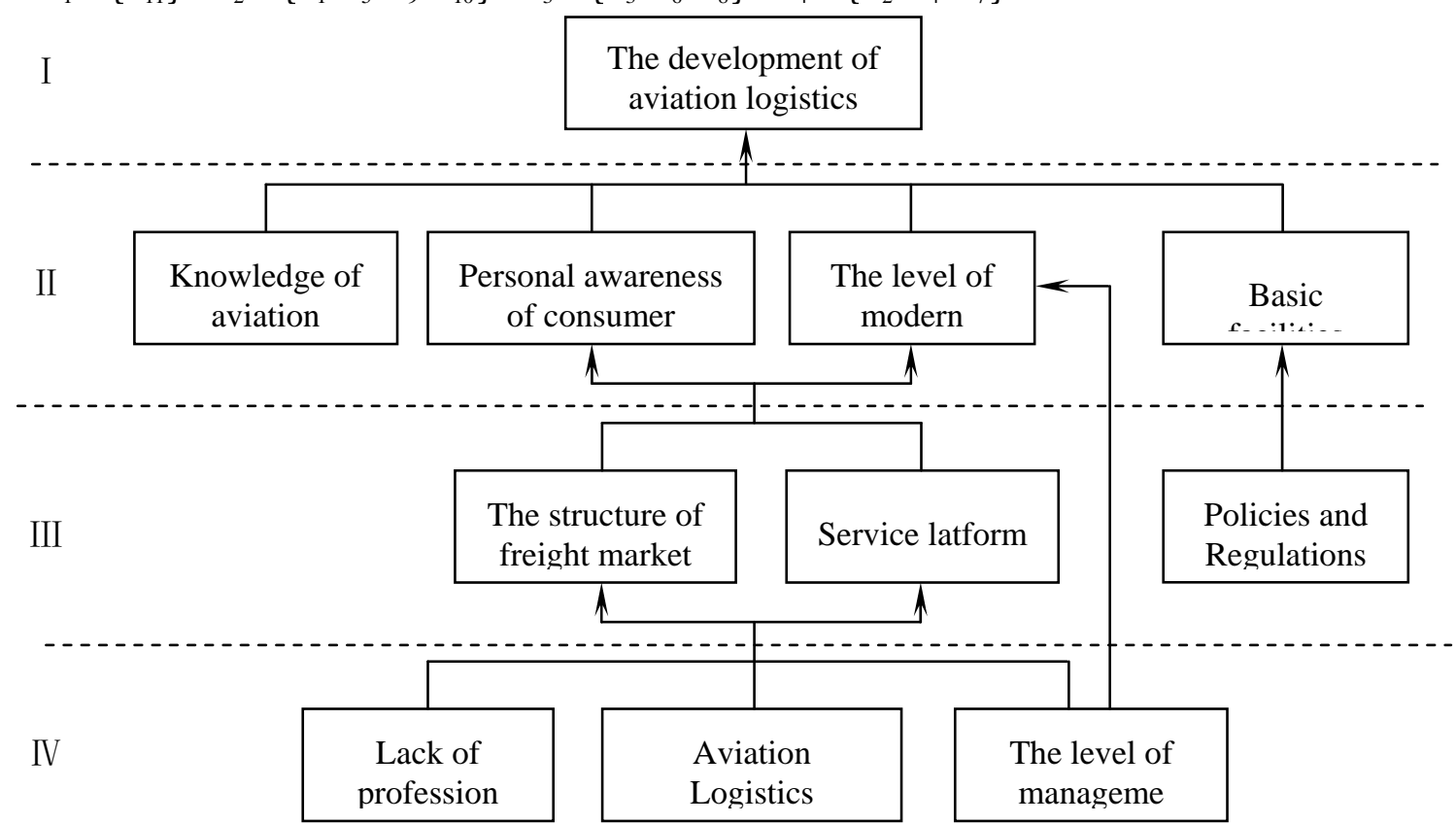

Fig. 2 Analysis of the development factors of Aviation Logistics based on ISM

\section{Interpretive structural modeling system}

According to the above analysis, the central plains aviation logistics factors system is divided into four levels (level I with element: 11, level II with elements: 1, 5, 9 and 10, level III with elements: 3, 6 and 8, level IV with elements: 2, 4 and 7), multilevel hierarchical structure model deduced by reachability matrix is shown in figure 2 : 
As shown in Figure 2, the analytical model clearly states these affecting factors with four hierarchy structure and the relationships between them of central plains aviation logistics system. The figure 2 also shows the apparent factors $\left(S_{1}, S_{5}, S_{9}, S_{10}\right)$, the middle factors $\left(S_{3}, S_{6}, S_{8}\right)$, and the underlying factors $\left(S_{2}, S_{4}, S_{7}\right)$.

\section{Conclusions}

Through the analysis of the developing influence factors of central plains aviation logistics, interpretive structural modeling method is used to study the relationship between various influencing factors. The interpretive structural modeling on influencing factors of central plains district aviation logistics system is deduced, and some conclusions are given in the following:

(1) Improving the underlying factors such as competency of professional, informatization construction and management level of aviation logistics. According to modern business management concepts, methods and measures, the management of enterprise should be completed, and it should be improved immensely about the ability of solving problem, resisting risk and improving competitiveness. The training of professional talents is a great benefit to the management level and the informationization construction of aviation logistics, which will not only improve efficiency, reduce cost and offer, but also provide customers with efficient, punctual, attentive service.

(2) The development of the aviation logistics is closely related to the support of the policy and regulation which can provide a good development environment for aviation logistics and help to establish the service platform to provide better quality service to consumers.

(3) Zhengzhou airport economic zone is under construction period, we must pay more attention to the construction of infrastructure because it is the basis of the aviation logistics industry. First we should increase the construction of logistics facilities, which include modern storage facilities, cargo handling centers, bonded logistics facilities, business office facilities, infrastructure facilities, specialized machinery, modernization equipment, and the rational distribution of logistics facilities. On the other hand, we should accelerate the improvement of transportation system, such as the connection between the airport and the fast roads of main industrial zone and cities.

(4) Effective operation of the modern logistics industry wouldn't develop without the support of the logistics information platform, the logistics industry is a service industries with cross-industry, cross-sectoral and cross-boundary. The diversity of the need of service generates the diversity of the logistics enterprises and service mode, which directly leads to the diversity and complexity of the logistics information which is an important part of the logistics system. Building a logistics business information platform is very necessary, which uses internet, intranet and other technical components to air cargo logistics services based online virtual trading market, namely the realization of electronic logistics transactions.

\section{References}

[1] Ma Tianshan, Dong Qianli. Basics of modern logistics. China Communications Press, 2005 (in Chinese).

[2] Dong Qianli. Advanced logistics. China Communications Press, 1999 (in Chinese).

[3] Wong Xingang. Basis of Logistics Management. Chinese Material Press, 2002 (in Chinese).

[4] Zhu Pei. Airline cargo conveyance tutorial. Weapon Industry Press, 2004 (in Chinese).

[5] Ma Zhijun. The Analysis of Logistics Professionals Education Methods of "Central Plains Economic Region”. LOGISTICS ENGINEERING AND MANAGEMENT. 2013, 35 (7): 204-206.

[6] Ju Hong. Study on Integration of Air Logistics Service Chain in Zhengzhou Air Harbor Economy Comprehensive Experimental Plot. LOGISTICS ENGINEERING AND MANAGEMENT. 2013, 35 (2): 8-10. 